\title{
Portfolio Performance Evaluation for LQ 45 Index in 2016-2020 Periods Using the Treynor Method
}

\author{
Wahidah Alwi ${ }^{1}$, Nurhafsari. B ${ }^{2, *}$, Ilham Syata ${ }^{3}$, Risnawati Ibnas ${ }^{4}$, Sri Dewi Anugrawati ${ }^{5}$ \\ 1,2,3,4,5 Mathematics Departement, Faculty of Science and Technology, Univesitas Islam Negeri Alauddin Makassar \\ *nurhafsaribahar@gmail.com
}

\begin{abstract}
This research discussed the portfolio performance evaluation using the Treynor method. The portfolio performance evaluation aims to assess the established portfolio whether had a good performance and suitable to the investment goals. At the research, a portfolio was selected based on the efficient stock by taking two criteria that were, the first, ( portfolio A ) based on the greatest positive expected returns and the second (portfolio B) based on the smallest positive risk (beta). The result showed from the formation of the portfolio are for portfolio A was selected AKRA and PTBA stocks, as for portfolio B was selected ICBP and BBCA stocks. Of these two portfolios, both had good performance since the index Treynor acquired had positive results and portfolio $\mathrm{B}$ had better performance than portfolio A.
\end{abstract}

Keywords: Performance evaluation, Treynor method, CAPM.

\section{INTRODUCTION}

Everyone is faced with various choices in determining the funds or resources they have for current and future consumption. Not a few people choose to invest to save the capital they have. Rampant stock trading in the capital market reflects the great investment interest of the public. Investments in securities are attractive because of the sizeable returns.

Besides, investment in securities has another attraction, namely the ease of investing. When investing, investors will not invest their capital in just one share, investors will invest their shares in several different stocks to minimize the risk of loss from falling share prices. For the right investment decision or to produce the expected return, investors need to make an initial assessment of the stocks they will choose cx.

The performance appraisal of stock generally starts with evaluating the stock return, whether it can provide a return that exceeds (above) other stock returns and whether the return obtained is following the level of risk that must be borne. For this reason, investors will usually diversify by forming a portfolio, namely by investing in many stocks so that the risk of loss on one share will be covered by the advantages of other shares. [1]

Informing a portfolio, several methods are used, one of which is the Capital Asset Pricing Model (CAPM). Investors need to be able to estimate the return of a single stock. For that, CAPM can estimate stock returns. However, measuring portfolio performance is not just looking at the return. [2] However, the risks that will be borne also need attention. Following the capital market theory, three methods can be used to measure portfolio performance. In its calculation, this performance measure includes the risk and return factors. This method was developed by Jack Treynor, Michael Jensen, and William Sharpe. Each of these measures is called the Treynor, Jensen, and Sharpe performance measure. [3]

Shares listed on LQ-45 are liquid stocks, have development prospects, financial conditions, and high sales value, and have been objectively selected by the Indonesia Stock Exchange. Therefore, the researcher decided to use the Treynor method where this method emphasizes beta fluctuations and portfolio 
performance will be said to be better if the Treynor index value is positive, and the bigger it is. So that in this thesis will use the data of stocks listed in LQ 45. Based on the case studies and analyzes that have been written, the authors are interested in discussing the Stock Portfolio Performance Analysis Using the Treynor Method.

\section{PORTFOLIO \& ASSET PRICING}

\subsection{Portfolio}

A portfolio is a collection of securities (securities). In 1956 Prof. Harry Markowitz first developed portfolio theory. This theory explains how to form an optimal portfolio from the many choices of efficient portfolios. [4]

\subsection{Return}

The general formula for total return between period $\mathrm{t}-1$ to $\mathrm{t}$ is as follows

$R_{t}=\frac{P_{t}-P_{t-1}}{P_{t-1}}$

$R_{t} \quad:$ total return

$P_{t} \quad:$ the investment price at time $t$

$P_{t-1} \quad:$ the investment price at time

$t-1$

The market return is a cumulative profit that describes all shares listed on the exchange [2]

$$
\begin{array}{ll} 
& R_{m}=\frac{I H S G_{t}-I H S G_{t-1}}{I H S G_{t-1}} \\
R_{m} & : \text { market return } \\
I H S G_{t} & : \text { IHSG price at time } t \\
I H S G_{t-1} & : \text { IHSG price at time } t-1
\end{array}
$$

The expected return is the weighted average of the returns of each stock in the portfolio. [5] The mathematically expected return is formulated as follows:

$$
\left(E\left(R_{p}\right)\right)=E\left(\sum_{i=1}^{n} w_{i} R_{i}\right)
$$

$$
\left(E\left(R_{p}\right) \quad:\right. \text { expected return portfolio }
$$$$
w_{i} \quad: \text { the individual stock weight }
$$

$\left(E\left(R_{i}\right) \quad:\right.$ the individual value of expectation of return from the stock

\subsection{Risk (Beta)}

Beta is a measure of risk that comes from the relationship between the rate of return of a stock and the market rate of return, or in other words, beta is the quotient between stock covariance and market variance. [5] Find the beta value of each stock using the equation

$\beta_{i}=\frac{\sigma_{i m}}{\sigma_{m}^{2}}$

$\beta_{i} \quad:$ estimation of the stock beta coefficient value

$\sigma_{i m} \quad:$ covariance of the stock return with the market return

$\sigma_{m}^{2} \quad:$ variance of the stock market

\subsection{Model of Capital Asset Pricing}

The CAPM model is a balance model that describes the relationship between return and risk to be simpler because it only uses a variable (also called a beta variable) to describe risk. Sharpe, Litner, and Mossin in the mid-1960s, introduced the CAPM. Markowitz put forward a portfolio theory called CAPM. Following the Markowitz model, it is assumed that each investor will diversify his portfolio and choose the optimal portfolio according to his preference for risk and return. The portfolio chosen by investors is the portfolio points that are on all efficient portfolio lines. [1]

The expected rate of return is the return desired by investors on investments made based on beta risk preference. Calculating the Expected Return of Shares using the equation.

$E\left(R_{i}\right)=R_{f}+\left(E\left(R_{m}\right)-R_{f}\right) \beta_{i}$

$E\left(R_{i}\right) \quad:$ return equilibrium stock

$R_{f} \quad:$ risk-free return value

$\beta_{i} \quad:$ estimation of the stock beta coefficient value

$\left(E\left(R_{m}\right)\right.$ : value of expectation of return from the market 


\subsection{Treynor Performance Measures}

This performance measure is measured by comparing the portfolio risk premium (the difference between the average portfolio return and the risk-free return) with the portfolio risk expressed by $\beta$ (market risk or systematic risk). [6] Portfolio performance is said to be good if the slope of the line is getting bigger that forms the line. The Treynor index can be systematically written as follows:

$$
T_{p i}=\frac{R_{p i}-R_{f}}{\beta_{p i}}
$$

$T_{p i} \quad:$ Treynor performance index

$R_{p i} \quad:$ portfolio return value

$R_{f} \quad:$ risk free return value

$\beta_{p i} \quad: \frac{\operatorname{cov}\left(R_{i}, R_{m}\right)}{\operatorname{var}\left(R_{m}\right)}=$ portfolio beta i

\section{RESULT AND DISCUSSION}

The data used in this study are monthly stock return data from companies listed on LQ-45 that have been registered from 2016 to 2020

\subsection{Individual Monthly Share Rate of Return and Market Return}

By using equation (1) we get monthly stock returns and equation (2) we get market returns.

\subsection{Risk-Free Return Rate}

The risk-free rate of return is used by investors to determine the rate of return on their investment. The Bank Indonesia interest rate (SBI) is the risk-free rate of return used. The calculation of the risk-free return is as follows:

$$
\begin{aligned}
R_{f} & =\frac{0.050815}{12} \\
& =0.004 \\
& =0.04 \%
\end{aligned}
$$

\subsection{Calculation of the Systematic Risk of Shares}

By using equation (4), the beta value can be obtained which can be seen in Table 1 .

Table 1. The result of the stock beta calculation

\begin{tabular}{c|c|c}
\hline $\mathbf{N}$ & Stock Code & $\boldsymbol{\beta}_{\boldsymbol{i}}$ \\
\hline $\mathbf{1}$ & AKRA & 1.52468 \\
\hline $\mathbf{2}$ & ASII & 2.29988 \\
\hline $\mathbf{3}$ & BBCA & 1.04799 \\
\hline $\mathbf{4}$ & BBNI & 1.8153 \\
\hline $\mathbf{5}$ & BBRI & 1.3386 \\
\hline $\mathbf{6}$ & BBTN & 1.77083 \\
\hline $\mathbf{7}$ & BMRI & 1.14977 \\
\hline $\mathbf{8}$ & BSDE & 1.46837 \\
\hline $\mathbf{9}$ & GGRM & 0.98903 \\
\hline $\mathbf{1 0}$ & ICBP & 0.59402 \\
\hline $\mathbf{1 1}$ & INCO & 1.81879 \\
\hline $\mathbf{1 2}$ & INDF & 0.99649 \\
\hline $\mathbf{1 3}$ & JSMR & 1.04107 \\
\hline $\mathbf{1 4}$ & KLBF & 1.34008 \\
\hline $\mathbf{1 5}$ & LPPF & 1.89284 \\
\hline $\mathbf{1 6}$ & MNCN & 1.72322 \\
\hline $\mathbf{1 7}$ & PGAS & 2.00083 \\
\hline $\mathbf{1 8}$ & PTBA & 2.03793 \\
\hline $\mathbf{1 9}$ & PTPP & 2.74179 \\
\hline $\mathbf{2 0}$ & SMGR & 1.75454 \\
\hline $\mathbf{2 1}$ & SRIL & 0.64032 \\
\hline $\mathbf{2 2}$ & UNTR & 1.0149 \\
\hline $\mathbf{2 3}$ & UNVR & -4.1601 \\
\hline $\mathbf{2 4}$ & WIKA & 2.17519 \\
\hline & &
\end{tabular}

From the results obtained, the share of the company that has the largest beta is PP Persero Tbk (PPTP) shares with a value of 2.74179. This shows that PTPP's share is aggressive stock because it has more than one beta $(\beta>1)$. On the other hand, the one with the smallest beta is Unilever Indonesia Tbk (UNVR) with a value of -4.1601 . 


\subsection{Level of Expected Return of Shares Using CAPM}

To find the expected return, equation (5) is used so that the expected return can be seen in Table 2.

Table 2. The result of expectation return from the stock

\begin{tabular}{c|c|c}
\hline $\mathbf{N}$ & Stock Code & $\boldsymbol{E}\left(\boldsymbol{R}_{\boldsymbol{i}}\right)$ \\
\hline $\mathbf{1}$ & AKRA & 0.00654 \\
\hline $\mathbf{2}$ & ASII & 0.00783 \\
\hline $\mathbf{3}$ & BBCA & 0.00574 \\
\hline $\mathbf{4}$ & BBNI & 0.00702 \\
\hline $\mathbf{5}$ & BBRI & 0.00623 \\
\hline $\mathbf{6}$ & BBTN & 0.00695 \\
\hline $\mathbf{7}$ & BMRI & 0.00591 \\
\hline $\mathbf{8}$ & BSDE & 0.00644 \\
\hline $\mathbf{9}$ & GGRM & 0.00565 \\
\hline $\mathbf{1 0}$ & ICBP & 0.00499 \\
\hline $\mathbf{1 1}$ & INCO & 0.00703 \\
\hline $\mathbf{1 2}$ & INDF & 0.00566 \\
\hline $\mathbf{1 3}$ & JSMR & 0.00573 \\
\hline $\mathbf{1 4}$ & KLBF & 0.00623 \\
\hline $\mathbf{1 5}$ & LPPF & 0.00715 \\
\hline $\mathbf{1 6}$ & MNCN & 0.00687 \\
\hline $\mathbf{1 7}$ & PGAS & 0.00733 \\
\hline $\mathbf{1 8}$ & PTBA & 0.00739 \\
\hline $\mathbf{1 9}$ & PTPP & 0.00856 \\
\hline $\mathbf{2 0}$ & SMGR & 0.00692 \\
\hline $\mathbf{2 1}$ & SRIL & 0.00506 \\
\hline $\mathbf{2 2}$ & UNTR & 0.00569 \\
\hline $\mathbf{2 3}$ & UNVR & -0.0029 \\
\hline $\mathbf{2 4}$ & WSKT & 0.00762 \\
\hline & &
\end{tabular}

Based on Table 2 above, shares of the company PP Perseo Tbk (PTPP) have the largest expected return of $0.00856 \%$ while Unilever Indonesia Tbk (UNVR) is the company stock with the lowest expected return with a value $0.0029 \%$. this means that the size of the expected return $E\left(R_{i}\right)$ depends on the size of the risk (beta) of the stock, in other words, the expected return $E\left(R_{i}\right)$ and risk (beta) have a positive relationship.

\subsection{Portfolio Formation}

This selection is based on the highest value of expected return and 4 companies were selected, namely PTPP, ASII, PTPP, and WSKT. Of the four stocks that are included in the efficient portfolio candidate, an opportunity is formed from the four stocks that will be used as an efficient portfolio. The stocks that are formed are as follows:

Table 3. Stocks that make up an efficient portfolio

\begin{tabular}{c|c}
\hline $\mathbf{N}$ & Portfolio \\
\hline $\mathbf{1}$ & PTPP \\
& ASII \\
\hline $\mathbf{2}$ & PTPP \\
& WIKA \\
\hline $\mathbf{3}$ & PTPP \\
& PTBA \\
\hline $\mathbf{4}$ & ASII \\
& WIKA \\
\hline $\mathbf{5}$ & ASII \\
& PTBA \\
\hline $\mathbf{6}$ & WIKA \\
& PTBA \\
\hline
\end{tabular}

\subsection{Calculating Portfolio Weights}

Calculating the portfolio weight using the equation:

$$
w_{i}=\frac{z_{i}}{\sum_{i=1}^{n} z_{i}}
$$

Table 4. Portfolio weighting result

\begin{tabular}{c|c|c}
\hline $\mathbf{N}$ & Portfolio & Weight \\
$\mathbf{1}$ & PTPP & 0.321 \\
& ASII & 0.679 \\
\hline $\mathbf{2}$ & PTPP & 0.971 \\
& WIKA & 0.083 \\
\hline $\mathbf{3}$ & PTPP & 0.260 \\
& PTBA & 0.740 \\
\hline $\mathbf{4}$ & ASII & 0.716
\end{tabular}




\begin{tabular}{c|c|c} 
& WIKA & 0.284 \\
\hline $\mathbf{5}$ & ASII & 0.364 \\
& PTBA & 0.636 \\
\hline $\mathbf{6}$ & WIKA & 0.175 \\
& PTBA & 0.825 \\
\hline
\end{tabular}

Based on Table 4 above, the largest share weight is in the 2nd portfolio, namely shares of the company PP (Persero) Tbk (PTPP) amounting to $91.7 \%$

\subsection{Calculation of Expected Return and Portfolio Risk}

Calculating the expected return and beta of the portfolio is necessary to determine the rate of return of the portfolio, how much return will be obtained on the selected portfolio, and the risk of the portfolio using the equation (3) and $\beta_{p}=$ $\sum_{i=1}^{n} w_{i} \beta_{i}$

Table 5. The result of expectation from the stock and portfolio beta

\begin{tabular}{c|c|c|c}
$\mathbf{N}$ & Portfolio & $\mathbf{E}(\mathbf{R p})$ & $\mathbf{B p}$ \\
\hline $\mathbf{1}$ & $\begin{array}{c}\text { PTPP } \\
\text { ASII }\end{array}$ & 0.00718 & 1.91522 \\
& & \\
\hline $\mathbf{2}$ & PTPP & 0.0081 & 2.69452 \\
& WIKA & & \\
\hline $\mathbf{3}$ & PTPP & 0.0076 & 2.2204 \\
& PTBA & & \\
\hline $\mathbf{4}$ & ASII & 0.0068 & 1.709 \\
& WIKA & & \\
\hline $\mathbf{5}$ & ASII & 0.00708 & 1.8511 \\
& PTBA & & \\
\hline $\mathbf{6}$ & WIKA & 0.0074 & 2.0618 \\
& PTBA & & \\
\hline
\end{tabular}

From the results of Table 5 above, the efficient portfolio is the second portfolio with an expected return of $0.81 \%$ and a beta of 2.69452 because it has the largest expected return compared to other portfolios, although the risk it has is not the smallest.

\subsection{Portfolio Performance Calculation Using the Treynor Method}

Portfolio performance is calculated by comparing the portfolio risk premium (the difference between the average portfolio return and the risk-free return) with $\beta$ (market risk or systematic risk) representing portfolio risk. Where the portfolio performance will be said to be getting better if the index value is getting bigger. Treynor index value for each portfolio.

Table 6. Index Treynor value

\begin{tabular}{l|l|l|l|l}
\hline $\mathbf{N}$ & Portfolio & E(Rp)-Rf & Bp & Treynor \\
\hline $\mathbf{1}$ & $\begin{array}{l}\text { TLKM } \\
\text { UNVR }\end{array}$ & 0.003187 & 1.91522 & 0.001664259 \\
\hline $\mathbf{2}$ & $\begin{array}{l}\text { TLKM } \\
\text { ASII }\end{array}$ & 0.004484 & 2.69452 & 0.001664453 \\
\hline $\mathbf{3}$ & $\begin{array}{l}\text { TLKM } \\
\text { INDF }\end{array}$ & 0.003695 & 2.2204 & 0.00166436 \\
\hline $\mathbf{4}$ & $\begin{array}{l}\text { UNVR } \\
\text { ASII }\end{array}$ & 0.002845 & 1.709 & 0.001664468 \\
\hline $\mathbf{5}$ & $\begin{array}{l}\text { UNVR } \\
\text { INDF }\end{array}$ & 0.003081 & 1.8511 & 0.001664468 \\
\hline $\mathbf{6}$ & $\begin{array}{l}\text { ASII } \\
\text { INDF }\end{array}$ & 0.003431 & 2.0618 & 0.001664429 \\
\hline
\end{tabular}

Based on Table 6 above, shows that the portfolio performance selected using the Treynor method has a positive Treynor index value. This shows that based on the Trenor method all selected portfolios have good performance.

\section{CONCLUSION}

Based on the calculations and discussion described in the previous chapter, it can be concluded that there are six combinations of stocks that make up a portfolio taken from the four stocks that have the highest expected return value. The four stocks that make up an efficient portfolio are PTPP, ASII, WIKA, and PTBA Of the six portfolios formed, namely the 1st portfolio (PTPP and ASII), 2nd portfolio (PTPP 
and WIKA), 3rd portfolio (PTPP and PTBA), 4th portfolio (ASII and WIKA), 5th portfolio (ASII and PTBA), the 6th portfolio (WIKA and PTBA) has good performance because it has a positive Treynor index value. In this study, the authors provide suggestions, namely that further researchers can use different methods in portfolio formation such as the Single Index Model or use other methods of calculating portfolio performance such as the Jensen method and the Sharpe method.

\section{REFERENCES}

[1] Guerard, J. B, Portfolio Construction, Measurement, and Efficiency. Springer Nature, USA, 2017, p 275.

[2] Treynor, J. L, Treynor on Institutional Investing, Simultaneously, Canada. 2007, p 87.

[3] Hubner, G, The Generalized Treynor Ratio. EDHEC Business School, University of Liege, 2003.

[4] Jozef, G, Time-Varying CAPM And Its Applicability In Cost Of Equity Determination, vol 32. Elsevier, Slovak Republic, 2015, p 62.

[5] Bodie, K.M, Investment, McGraw-Hill Education, 2014 p 164.

[6] Suriyani, A., The Analysis Of Risk-Adjusted Return Portfolio Performance Share for LQ 45 Index in Indonesia Stock Exchange In 2010-2014 Periods, vol 211, Elsevier, Bali, 2015, p 639. 